Consumo alimentar e cultura material: um estudo sobre distinções e escolhas alimentares entre moradores de um conjunto habitacional popular.

Revista Ensaios, vol. 13, jul-dez de 2018. ISSN 2175-0564.

\title{
Consumo alimentar e cultura material: Um estudo sobre distinções e escolhas alimentares entre moradores de um conjunto habitacional popular
}

\author{
Shirley Torquato ${ }^{1}$ \\ Marcelo Garson ${ }^{2}$
}

\section{Resumo}

Este artigo tem como objetivo refletir sobre os processos de significação, circulação, consumo e hábitos alimentares de um grupo de moradores do conjunto habitacional PAC Morro do Preventório, localizado no município de Niterói, estado do Rio de Janeiro. Tais moradores foram removidos de áreas de risco da favela do Preventório, em 2010, para 248 unidades habitacionais, construídas em terrenos nos arredores da favela, através do Programa de Aceleração do Crescimento - PAC. Paralelamente à análise do campo empírico, o artigo busca realizar uma revisão de alguns estudos sobre alimentação desenvolvidos nas Ciências Sociais.

Palavras-chave: Alimentação, PAC Morro do Preventório, Consumo.

Food consumption and material culture: A study about distinctions and food choices among residents of a popular housing

\begin{abstract}
The purpose of this paper is to analyse processes of significance, circulation and food consumption of a group of residents of the housing complex "PAC Morro do Preventório", located in the municipality of Niterói, state of Rio de Janeiro. These residents were moved in 2010 from the Preventorio slum to 248 housing units built around the favela through the Programa de Aceleração do Crescimento, Growth Acceleration Program, (PAC), which aimed reallocating residents living in areas considered at risk. Parallel to the analysis of the empirical field, the article also seeks to carry out a review of the main food studies carried out in the social sciences.
\end{abstract}

Keywords: Food, Growth Acceleration Program, Consumption.

\footnotetext{
${ }^{1}$ Doutora em Antropologia pela Universidade Federal Fluminense. Docente do curso de MBA em Ciências do Consumo, da Escola Superior de Propaganda e Marketing- ESPM- RJ. Integrante do Núcleo de Estudos da Modernidade- NEMO- PPGA-UFF. E-mail: Stshirleytorquato1@ gmail.com.

${ }^{2}$ Doutor em Sociologia pela USP e professor do Departamento de Comunicação da Universidade Federal do Paraná. E-mail: garson.marcelo@gmail.com.
} 
Consumo alimentar e cultura material: um estudo sobre distinções e escolhas alimentares entre moradores de um conjunto habitacional popular.

Revista Ensaios, vol. 13, jul-dez de 2018. ISSN 2175-0564.

O interesse em estudar os hábitos alimentares dos moradores do "PAC Morro do Preventório", ocorreu durante uma pesquisa mais complexa de cunho etnográfico realizada na região entre 2010 a 2013. Na ocasião, a proposta consistiu em analisar os impactos da mudança de endereço na mudança dos padrões de consumo das famílias contempladas com os apartamentos. Embora a intenção inicial fosse a análise da cultura material deste grupo de moradores, a temática da alimentação se mostrou um ponto crucial, pois a racionalização e esquematização do novo orçamento doméstico passaram a ser pensadas a partir das despesas alimentares (TORQUATO, 2013).

A proposta metodológica utilizada na composição deste artigo partiu da descrição etnográfica do campo empírico, com a tomada de alguns casos específicos para contextualizar a centralidade da alimentação no âmbito doméstico. Concomitantemente, foi realizada uma revisão bibliográfica acerca da alimentação no universo das Ciências Sociais.

\section{Localizando o Morro do Preventório}

A Favela do Preventório, a mais populosa de Niterói, segundo dados do IBGE (2010), está situada no bairro de Charitas, em frente à orla da Baía de Guanabara, mais especificamente em frente à Praia de Charitas, também chamada pelos moradores de Praia do Preventório. Nesta mesma orla está localizada a Estação Hidroviária que faz a travessia Charitas-PraçaXV, região central da capital. Na rua principal, avizinham-se prédios residenciais, restaurantes, hotéis e edificações públicas. Nas imediações da favela, há uma grande área de preservação ambiental, o que não impediu, a poucos metros de distância, a construção de condomínios residenciais de classe média.

As obras de urbanização da Favela do Preventório, segundo o Ministério das Cidades, foram orçadas em 22 milhões de reais, incluindo obras de urbanização; reflorestamento e contenção de encostas; construção de um Centro Comunitário; uma praça e uma quadra poliesportiva e reassentamento de famílias que ocupam áreas de proteção ambiental. Em períodos de chuvas, é comum ocorrerem alagamentos, enchentes e deslizamentos de terras. Nessas ocasiões, muitas famílias perdem seus pertences, suas casas e até mesmo suas vidas. No Preventório, essas histórias se repetem anualmente, por isso, ali, as obras de contenção 
Consumo alimentar e cultura material: um estudo sobre distinções e escolhas alimentares entre moradores de um conjunto habitacional popular.

Revista Ensaios, vol. 13, jul-dez de 2018. ISSN 2175-0564.

sempre foram necessárias e urgentes. A militância da Associação de Moradores, paralelamente aos interesses do município e do estado em valorizar ainda mais aquela área urbana, foi fundamental para que a comunidade fosse servida pelas intervenções do Programa (TORQUATO, 2013).

Aproximadamente 800 moradores foram morar nas 238 unidades habitacionais. Além destas, dez unidades foram disponibilizadas para internos do hospital psiquiátrico de Jurujuba, localizado ao lado da favela, totalizando 248 apartamentos ${ }^{3}$.

\section{Alimentação - A primeira conta a pagar}

O aumento no custo de vida que a ida para os apartamentos exigiu ocorreu não apenas por conta das despesas com os serviços regulares, mas também devido ao fato de que queriam colocar em prática desejos antigos que passaram a ser vistos como necessidades, como adquirir novos móveis e eletrodomésticos para facilitar a rotina e decorar a moradia, sem deixar "faltar alimento pra dentro de casa", como relatou a moradora Simone.

$\mathrm{Na}$ ocasião do cadastramento dos moradores, a renda média destas famílias era de até dois salários mínimos mensais, incluindo trabalhos extras e eventuais benefícios do governo, como o benefício Bolsa Família.

A preocupação com o pagamento das contas de gás, luz e as compras com alimentação estavam no mesmo nível de importância, pois o preparo dos alimentos está atrelado ao gás, e a sua manutenção, através da geladeira. Ficou claro que as despesas com alimentação superaram todas as demais.

Não havia, como era de se esperar, um padrão de consumo homogêneo entre os moradores, mas, naquela ocasião, era comum observar que os gastos com alimentação não se

\footnotetext{
${ }^{3}$ A remoção das famílias de suas casas da favela para os apartamentos foi norteada por ambiguidades. Muitos foram os conflitos gerados pelas ansiedades, incertezas, e novas expectativas diante do que chamavam de "nova vida". No entanto, mesmo não sendo inicialmente escolhida ou desejada, e sim imposta por um programa de governo, a nova moradia foi pouco a pouco sendo transformada na "casa toda arrumadinha", conforme uma expressão nativa igualmente presente e recorrente em todos os depoimentos. Todos os moradores, que tiveram suas casas condenadas pelos técnicos contratados pelo Programa, tiveram que desocupá-la indo para os apartamentos ou recebendo uma pequena indenização, considerada irrisória e desvantajosa, logo, foram poucos os moradores que fizeram essa última opção. No período de 15 meses foram visitados 65 apartamentos
} 
Consumo alimentar e cultura material: um estudo sobre distinções e escolhas alimentares entre moradores de um conjunto habitacional popular.

Revista Ensaios, vol. 13, jul-dez de 2018. ISSN 2175-0564.

reduziam à itens considerados pelo senso comum como essenciais para a sobrevivência. Assim, era com enorme orgulho que mostravam suas geladeiras e congeladores com variedades de carnes, laticínios, cervejas, refrigerantes, sobremesas, biscoitos e doces para as crianças. Ter a geladeira cheia indicava a sensação de "dever cumprido". Da Matta (1985) explica que o consumo considerado "desmedido e exagerado" é uma espécie de "ritual" que permite que o dono da casa afirme sua posição de superioridade social frente aos demais. Este paradoxo nos leva ao debate acerca do consumo, no qual o autor sugere que nem sempre os mais ricos são os que consomem mais.

Seja como for, a representação da fartura como um valor moral, também relacionada à honra, ambas expressas na forma da dádiva e do potlach (comensalidade), estava sempre presente em todas as cozinhas que visitei, e era ela que norteava e orientava a organização daquele cômodo. Não por acaso, as vedetes, os objetos astros da cozinha, eram a geladeira nova, grande, imponente, bem como os armários repletos de compras, panelas e utensílios utilizados na preparação das comidas.

A respeito da nova preocupação estética com a casa, as cozinhas eram mais do que pretextos para muitas conversas, não apenas sobre comida e comensalidade, mas também sobre a própria cultura material, mobílias e equipamentos recém adquiridos como a geladeira, fogão e armários.

Seria admissível supor que a cozinha fosse considerada o primeiro cômodo em importância, em função da prioridade que a alimentação possui na vida doméstica. Mas, tal perspectiva poderia incorrer num tipo de reducionismo, ao supor que famílias mais pobres vivem totalmente às voltas com suas necessidades básicas.

Wortmam (1982) ao analisar famílias rurais no Brasil, identifica de forma nítida a organização hierárquica no que se refere a composição dos pratos à mesa, donde obedece a um padrão de gênero e etário: os homens, os velhos e as crianças. Os primeiros, por representarem o domínio da família e os dois últimos, por uma questão de vulnerabilidade e necessidades especiais.

Maciel (1996) indica que o que a presença de pratos fartos em quantidade e em calorias representa para as classes populares urbanas a ideia de uma "boa alimentação". A 
Consumo alimentar e cultura material: um estudo sobre distinções e escolhas alimentares entre moradores de um conjunto habitacional popular.

Revista Ensaios, vol. 13, jul-dez de 2018. ISSN 2175-0564.

fartura à mesa permite a produção de "sustância", importante categoria nativa, e força, elementos fundamentais para o favorecimento da manutenção dos corpos saudáveis para o trabalho. Rial (1996), Canesqui (2005), Lívia Barbosa (2007) partilham da mesma análise em diferentes trabalhos de pesquisa. Livia Barbosa, no entanto, problematiza a reflexão bourdesiana, que explicita que os modos de preparo, cocção, e consumo dos alimentos nos diferentes grupos socioeconômicos estão em grande medida ancorados na ética das necessidades, para as classes populares e na ética do refinamento, nas elites. A concepção "das necessidades", no entanto, pontua a autora, pode vir a ser relativizada em diferentes circunstâncias, não somente em situações rituais, como festas e aniversários, mas principalmente é marcada por preferências e escolhas individuais. Ou seja, os pobres não hierarquizam suas preferências em torno do consumo alimentar apenas mediados por necessidade "básicas" e sim, por conta de preferências ou tradições. Nesse sentido, reforça a presença marcante do feijão com arroz no prato do brasileiro, observação anteriormente enfatizada por Da Matta (1986), no clássico, O que faz o brasil, Brasil.

\section{Distinção através do prato - Uma breve reflexão sobre a Alimentação nas Ciências Sociais}

É por volta da década de 1980 que a alimentação se torna um campo de investigação mais consolidado nas Ciências Sociais (MINTZ, 2001). Ainda assim, é possível pinçar diversas referências sobre o tema na literatura clássica. É o caso de A situação da classe trabalhadora na Inglaterra, em que Engels comenta a péssima condição alimentar do proletariado inglês. Já nas Regras do Método Sociológico, Durkheim encara a alimentação como tarefa de socialização primária. Um imperativo biológico, assim, se torna um aprendizado coletivo cercado de convenções e proibições que introduzem os indivíduos no jogo de regras que compõem a vida social. Isso fica claro em As formas elementares da vida religiosa, quando o mesmo autor relaciona o estudo da comida às interdições totêmicas e às distinções entre sagrado e profano. No entanto, esses primeiros estudos não tomam a alimentação como objeto específico (GOODY, 1998). 
Consumo alimentar e cultura material: um estudo sobre distinções e escolhas alimentares entre moradores de um conjunto habitacional popular.

Revista Ensaios, vol. 13, jul-dez de 2018. ISSN 2175-0564.

Uma exceção notável é o curto artigo de Simmel (1997), The sociology of the meal, escrito em 1910, que mostra como a alimentação é um pacto social que regula como, quando, com quem e em que ordem a refeição se organiza. Tocando rapidamente nos modos à mesa e na estetização da comida, antecipa temas que depois seriam tratados por Norbert Elias (1990) e Pierre Bourdieu (2007).

No campo da Antropologia, a alimentação aparece muito cedo nas etnografias clássicos, compondo, no entanto, mais um dentre os tantos itens que descrevem os modos de vida dos nativos. Algumas exceções estão em autoras como Audrey Richards, discípula de Malinowski, que em Land, Labor and Diet in Northern Rhodesia investigou como as tarefas de produção, preparação e consumo alimentar desempenhavam um importante papel na manutenção dos ciclos de vida, das relações interpessoais e estruturas sociais. Bem mais tarde, na década de 70, Evans-Pritchard em seu estudo sobre os Nuer observou uma íntima conexão entre o sistema de parentesco e a organização espacial dessa sociedade pastoril, afirmando que seu sistema alimentar estabelecia uma relação de simbiose com o rebanho. Isso quer dizer que, para além dos laços de parentesco, os indivíduos eram ligados através do gado (GOODY, 1998).

Uma visão diversa está nos estruturalistas, que olhavam não só para a alimentação, mas antes para a cozinha. $\mathrm{O}$ foco se desloca das práticas para as regras que organizam as práticas. Agora a cozinha funciona como uma linguagem, através da qual as sociedades traduzem suas categorias de pensamento inconscientes e revelam suas contradições. Assim, Lévi-Strauss buscaria compreender as estruturas culinárias da mesma forma que havia feito com as estruturas do parentesco. A partir da analogia com a linguagem, ele busca estudar a gramática que governa a classificação, produção e preparação dos alimentos (LÉVISTRAUSS, 1975). Ao comparar a cozinha francesa e a inglesa, toma os "gustemas" como as unidades culinárias mínimas. Elas se organizam a partir de estruturas de oposição e correlação - endógeno versus exógeno, central versus periférico - e, quanto ao sabor marcado versus não marcado - que traduzem, por sua vez, as diferenças entre local e exótico, prato principal versus guarnição e sabor forte versus suave. O que diferenciaria os sistemas culinários é a ênfase das oposições endógeno versus exógeno, além de central versus periférico - no caso inglês - para marcados versus não marcado - no caso francês. 
Consumo alimentar e cultura material: um estudo sobre distinções e escolhas alimentares entre moradores de um conjunto habitacional popular.

Revista Ensaios, vol. 13, jul-dez de 2018. ISSN 2175-0564.

Mas a maior contribuição de Lévi-Strauss está, provavelmente, em seu famoso triângulo culinário (1979), um esquema que tem por objetivo entender como os alimentos ajudam a operar a distinção entre natureza e cultura. Nos vértices do triângulo localizam-se os estados dos alimentos: cru, cozido e podre. O cozido é a transformação cultural do cru enquanto o podre é a sua degradação natural. A passagem do cru ao cozido só pode se operar com a manipulação do fogo, sinal do controle da natureza e conquista da cultura por parte do homem.

De maneira geral, a preocupação dos demais estruturalistas não recaiu na distinção entre natureza e cultura, tão cara a Lévi-Strauss, estando, ao contrário, mais concentrada nos sistemas culinários e suas classificações. Nessa perspectiva, é fundamental a noção de que é através do adestramento cultural que o indivíduo ingressa em um universo segmentado, já dotado de estruturas e categorias de julgamento. O objetivo da análise, a partir de então, é descobrir o que diferentes princípios de organização alimentar revelam sobre as sociedades.

Isso levou Mary Douglas (DOUGLAS, NICOD, 1975) a investigar como a organização das refeições da classe trabalhadora inglesa constituía um sistema estruturado. Apreender o significado de cada refeição era dar conta de sua posição em relação às outras. Nesse tocante, algumas refeições são mais resistentes às mudanças, como o assado de domingo, e outras, mais aptas à inserção ou retirada de itens, é o caso do café da manhã e dos lanchinhos (snacks). Todas elas compunham um sistema regulado por hierarquias, limites, inclusões e exclusões. Ainda que fosse comum beber com estranhos em locais públicos, compartilhar a comida era uma prática iminentemente familiar e realizada em casa. Assim, a refeição demarcava limites sociais: quando um indivíduo era convidado para comer ele estaria, também, cruzando esses limites.

Bastante influenciado por Lévi-Strauss, de quem herdou a ênfase nas estruturas e sistemas de oposição que explicam a conduta humana, Bourdieu (2006) contribuiu decisivamente para mostrar como o consumo cultural se inscreve em um sistema de regras que traduzem divisões sociais objetivas e também subjetivas. O seu foco são as classes sociais, mas o que as distingue não é somente a quantidade de capital econômico, mas, fundamentalmente, o volume de capital cultural. Essa é a propriedade que regula a distância, 
Consumo alimentar e cultura material: um estudo sobre distinções e escolhas alimentares entre moradores de um conjunto habitacional popular.

Revista Ensaios, vol. 13, jul-dez de 2018. ISSN 2175-0564.

entre grupos e indivíduos, em relação aos bens da cultura legítima e aos modos consagrados de usufruí-los.

As classes se distinguem por meio do habitus, conceito que traduz um sentido de orientação social, presente em modos de ser, pensar e agir inscritos na mente e também no corpo dos indivíduos. O habitus é o mediador entre indivíduo e sociedade, ele explica como a ação individual está moldada por constrangimentos sociais internalizados que passam a guiar as tomadas de posição dos indivíduos. A sociedade, com toda a sua estrutura desigual, deposita-se nas mentes dos indivíduos, que as transformam em categorias de distinção que orientam as tomadas de posição em situações particulares. As estruturas sociais tornam-se, assim, estruturas mentais, o que permite falar em "interiorização da exterioridade e exteriorização da interioridade" (BOURDIEU 1983, p.47). Nesse ponto, Bourdieu reconhece seu débito com Marcel Mauss (2003), que já havia lidado com o conceito de habitus para mostrar como o corpo humano não é um dado natural, sendo antes treinado e modelado socialmente.

Ao comparar os hábitos alimentares da burguesia e das classes populares, Bourdieu (2007) busca compreender sua lógica estruturante e o que revelam sobre os mecanismos de distinção social. Quanto mais se sobe na escala social, maior é a inclinação à estetização, à frugalidade e à cerimônia frente aos alimentos. Trata-se do exato oposto do que se vê nas classes populares: o gosto pela fartura, por comidas mais nutritivas e pela "informalidade". Aqui, o gosto seria moldado pela "necessidade" e na burguesia pela "liberdade", sendo o segundo só apreensível enquanto uma atitude de negação e de afirmação da diferença em relação ao primeiro.

Ou seja, as elites se constroem enquanto elites por não estarem presas ao alimento por uma relação de sobrevivência. A possibilidade de estetizar o que comem é uma expressão do poder que as distingue. Se as classes populares se permitem comer em frente à televisão, em porções fartas, não obedecendo a uma sequência que toda a família deve seguir; a burguesia preocupava-se com a disposição e apresentação dos pratos, com a ordem da refeição e com o controle estrito dos ruídos corporais e de qualquer sinal que possa indicar uma relação "natural" - não mediada culturalmente - com o alimento. O primado da substância se opõe ao da forma. 
Consumo alimentar e cultura material: um estudo sobre distinções e escolhas alimentares entre moradores de um conjunto habitacional popular.

Revista Ensaios, vol. 13, jul-dez de 2018. ISSN 2175-0564.

A oposição entre hábitos alimentares não só opõe a burguesia às classes populares, mas também opera nas frações de classes. Ao tratar ainda dos professores, fração dominada da classe dominante, ricos em capital cultural, mas não em capital econômico, identifica neles um gosto por culinárias estrangeiras ou regionais. Não possuindo os mesmos recursos da alta burguesia, fazem da originalidade uma maneira de se distinguir ao menor preço possível. Mas como já visto, a noção de necessidade, sublinhada por Bourdieu, é relativizada no trabalho de Lívia Barbosa.

O trabalho de Bourdieu encontra uma notável influência da obra de Norbert Elias (1990), que mostrou como a emergência de uma sociedade de corte na França foi acompanhada de um severo processo de adestramento corporal, que implicou em um sem número de códigos que se expressavam em comportamentos cotidianos, dos mais banais, aos mais íntimos. Quanto à alimentação, o emprego dos talheres, as porções individuais e as regras de etiqueta à mesa tornaram-se signos da repressão aos instintos, o que exprime a ação de um processo civilizador, título de um dos seus livros mais notáveis. A importância da obra para o debate sobre distinção está no fato de mostrar que o refinamento dos gostos operava como elemento de disputa entre uma aristocracia já estabelecida, que corria o risco de perder seu lugar social, e uma burguesia ascendente, em busca de reconhecimento nos salões reais.

É no marco desse processo de distinção que emerge a alta gastronomia, um fenômeno exclusivamente francês e que não se repetiu em países próximos, também dotados de uma corte, como a Inglaterra. Ao analisar esse processo em All Maners of Food, Stephen Mennell (1985) mostra que a alta gastronomia está intimamente ligada ao processo distintivo que envolvia a alimentação. Nesse jogo entre estabelecidos e outsiders, o que estava em jogo ali era a manutenção da identidade social da nobreza francesa em um período de incerteza e mudança.

Para Bourdieu, portanto, o que define uma classe social não é a posição objetiva na estrutura produtiva, como acreditava Marx, mas antes um habitus; uma identidade social que, estando ameaçado por conta de um grupo recém-chegado, se põe em atitude defensiva. No entanto, a alimentação não opera somente em termos de classe social, mas também de gênero. $\mathrm{Na}$ medida em que a diferença entre homens e mulheres é modelada socialmente, é necessário perceber como os alimentos participam desse processo. Bourdieu (2007, p.185) 
Consumo alimentar e cultura material: um estudo sobre distinções e escolhas alimentares entre moradores de um conjunto habitacional popular.

Revista Ensaios, vol. 13, jul-dez de 2018. ISSN 2175-0564.

chega a tratar do tema, quando percebe que a divisão sexual do trabalho também adentra o campo da alimentação. Às mulheres compete preparar e oferecer a comida. Além disso, na hora de se servirem, ainda arcam com o ônus de controlarem a quantidade de comida em seus pratos, enquanto o ato de fartar-se, sendo o oposto da conduta feminina, torna-se para os homens prova mesma de sua masculinidade.

Assim como no diagnóstico de Bourdieu, o prazer da fartura se torna um dever. Bourdieu também analise a multiplicação das subculturas alimentares nos anos 60, fenômeno ligado ao nicho contracultural, que apesar de tentar fugir às classificações do mercado de massa, se aproximava bastante, em suas temáticas, da "vulgata publicitária - há muito tempo acostumada a falar a linguagem do desejo" (BOURDIEU, 2007, p.349). A análise dessa nova classe média contracultural chama atenção para o início do processo de multiplicação das subculturas alimentares, hoje em franca expansão. Ainda que possuam um forte componente classista, seus códigos internos possuem uma riqueza e complexidade que não se esgotam nessa dimensão.

O processo de formação de nichos nos interessa em particular. Sua multiplicação é um dos aspectos mais salientes da paisagem alimentar contemporânea. A tentativa de fugir das classificações, abordada por Bourdieu, também aparece no trabalho de James Cronin (CRONIN, MCCARTHY, COLLINS, 2014) que investiga como a subcultura hipsters formada por indivíduos cuja distinção se faz pela valorização do "alternativo" em oposição ao "mainstream" - se utilizam da alimentação enquanto forma de afirmar a resistência ao mercado massivo, o que, paradoxalmente, não deixa de ser uma maneira de negociar uma representação de si nesse mesmo mercado. Nesse sentido, ao mesmo tempo em que evitam certas marcas de alimentos e optam por opções vegetarianas ou veganas, os hipsters praticam a "descomodificação", que é a prática de ressignificar itens massivos transformando-os em emblemas distintivos. Um dos exemplos citados pelo autor está na confecção de um bolo inteiramente feito de produtos de marcas conhecidas, mas que ganha seu diferencial quando incorpora o formato "kitsch" de um personagem de desenho animado da década de 70 . Segundo Cronin, é através desses hábitos alimentares que os indivíduos negociam sua distinção social, fundada na crença em uma posição fora das hierarquias estabelecidas. O que 
Consumo alimentar e cultura material: um estudo sobre distinções e escolhas alimentares entre moradores de um conjunto habitacional popular.

Revista Ensaios, vol. 13, jul-dez de 2018. ISSN 2175-0564.

está em jogo aqui é uma distinção subcultural fundada na noção de um estilo de vida extremamente particular.

A "nichificação" do consumo alimentar e a complexidade dos sistemas gastronômicos modernos, abordada por Cronin, ajusta-se à noção de gastro-anomia, cunhada por ClaudeFischler (1990). Em uma sociedade pós-tradicional, dotada de múltiplos e contrastantes sistemas de prescrição alimentar, Fischler considera que os indivíduos não mais dispõem de um terreno seguro no qual possam ancorar suas decisões em termos de alimentação. Esse gancho é útil para pensarmos de que maneira o fenômeno da globalização amplia o debate sobre a diversidade alimentar para uma lógica que extrapola a dimensão das classes sociais.

A formação da alta gastronomia francesa esteve intimamente ligada ao processo de lutas por distinção que envolveram nobres e burgueses. Já a Alemanha construiu sua identidade culinária ao reivindicar "simplicidade" e "naturalidade" contra os "exageros" franceses tão em voga entre a classe média daquele país (MOHRING, 2008). Durante o século XX, no entanto, os processos de formação de identidades culinária se tornaram bem mais complexos ao mobilizar uma série de representações que circulam para além das fronteiras nacionais.

Esse é o caso da dieta mediterrânea como uma invenção dos Estados Unidos. Tudo começou quando a dieta foi eleita a grande responsável pelos altos índices de doenças cardiovasculares entre os norte-americanos. O menor grau de incidência da enfermidade foi detectado na Grécia e Sul da Itália, após um rigoroso estudo comparado entre sete países, que se iniciou na década de 50 e durou mais de 30 anos. Mas é só na década de 90 que a alimentação à base de azeite, peixes, legumes e cereais é rotulada como "dieta mediterrânea". Chancelada pela medicina, essa nova identidade gastronômica se solidificou através da indústria cultural, mediante reportagens, livros de receita e programas de culinária. A partir daí os povos mediterrâneos constroem-se como os "outros" saudáveis, através de uma dieta supostamente ancestral, e que estaria prestes a se extinguir por conta da industrialização alimentar. Seria hora de resgatar esse "saber milenar" para o bem de todos (TAPPER, ZUBAIDE, 1996). 
Consumo alimentar e cultura material: um estudo sobre distinções e escolhas alimentares entre moradores de um conjunto habitacional popular.

Revista Ensaios, vol. 13, jul-dez de 2018. ISSN 2175-0564.

Esse caso nos mostra que as culturas alimentares, para se construírem, necessitam de um investimento simbólico que lhe dê suporte. A dieta mediterrânea só existe a partir do momento em que determinados ingredientes, modos de cozinhar e servir os alimentos são selecionado em detrimento de outros, afinal nem todos os povos mediterrâneos se alimentam da mesma forma. Mas o mais importante é a embalagem semântica do conjunto. Ao consumir essa dieta, consome-se também uma narrativa de alteridade pontuada de exotismo, mistério e saberes milenares. Assim, o mediterrâneo afirma-se como invenção norte americana, da mesma forma que o Oriente já se afirmou como invenção do Ocidente (SAID, 2007). Essa rápida revisão bibliográfica nos ajudou a compreender a dimensão simbólica da alimentação. Agora resta perceber como esse aspecto se fez presente no cotidiano das famílias moradores do PAC Morro do Preventório.

\section{Os custos da mudança e impacto na alimentação no PAC Preventório}

Os serviços regulares de energia elétrica, gás encanado, água, esgoto e manutenção do condomínio, passaram a ser vistos, para os moradores mais pobres, como uma punição ou mesmo, uma troca injusta. $\mathrm{O}$ relato da moradora Aline resume essa aflição:

Eu preferia viver lá no meu barraco sem ninguém me obrigar a nada. Eu não vou pagar condomínio e deixar de alimentar os meus filhos. Querem obrigar a gente a morar nesse apartamento, mas eu não preciso disso, só preciso dar de comer a eles. Disseram que os caras lá deram esse apartamento pra gente, mas é tudo mentira. Nunca vi darem uma coisa que a gente vai ter que ficar pagando pra sempre. Lá no morro eu tinha tudo isso e não pagava nada.

No caso exemplar da moradora Aline, o desejo de permanecer na favela e continuar utilizando os serviços de forma irregular, reforça a incapacidade de gerir financeiramente a sua vida e, mais ainda, reforça o fato de que o exercício de sua cidadania foi vivenciado de forma superficial. Para ela, que aos 22 anos possuía apenas escolarização primária, a imposição de direitos universais funcionou de forma opressora e violenta. Pois, sobreviver era o que mais lhe importava e a sobrevivência significava ter condições financeiras de alimentar a sua família e a si própria. 
Consumo alimentar e cultura material: um estudo sobre distinções e escolhas alimentares entre moradores de um conjunto habitacional popular.

Revista Ensaios, vol. 13, jul-dez de 2018. ISSN 2175-0564.

Seja como uma cidadania relacional (DAMATTA,1986), seja como uma cidadania regulada (SANTOS, 1979), há uma concordância entre ambos autores de que a cidadania brasileira está pautada em concepções hierárquicas, não se caracterizando como universal, mas como produtora de desigualdades, distinguindo cidadãos e não cidadãos. Configura-se, assim, uma cosmologia anti-igualitária (MOTA, 2005), que, ao ser pensada como igual, investe-se de caráter tutelar.

O Sr. Crisântemo, na ocasião da pesquisa, tinha 55 anos, era solteiro, sem filhos e morava sozinho em um apartamento de térreo, adaptado para idosos e deficientes físicos. Ascensorista desempregado, não tinha nenhuma renda. Devido a uma paralisia em sua perna esquerda, adquirida na infância, tinha dificuldade para locomoção e, ao longo da vida, criou redes de apoio numa igreja católica na cidade e com amigos e clientes na principal avenida de Niterói, onde trabalhou como engraxate. Essas redes lhe asseguraram por muitos anos, a aquisição de uma cesta básica mensal, e, além dela, todos os domingos ganhava um frango assado de um conhecido, que era funcionário de uma padaria, próxima ao Preventório. Com a ida para o apartamento, este amigo passou a lhe negar o benefício, pois não o via mais como pobre. Constrangido ao ouvir a justificativa do amigo, Crisântemo abandonou o apoio das outras redes, pois também chegou à conclusão de que não era mais pobre, devido a sua nova moradia. No entanto, começou a ter dificuldades para pagar não só as contas referentes ao apartamento, como para se alimentar.

Com o desabamento de sua casa em 2009, devido às fortes chuvas, Dona Gisela 63 anos, viúva, diarista e que durante a pesquisa morava com as duas netas (de 5 anos e 6 anos) ficou sem seus pertences e foi obrigada a morar por cerca de um ano num abrigo disponibilizado pela Prefeitura.

Neste período, ela passou temporadas na casa de parentes e amigos, até reconstruir pouco a pouco o que perdeu e voltar para casa. Desde o final de 2010, quando foi para o apartamento do PAC, a moradora estava convencida de que havia ganho um "presente de Deus”. Seus rendimentos incluíam uma pensão, que correspondia à um salário mínimo, diárias de faxinas, passagens de roupa e o benefício do Bolsa Família das netas, que lhe rendiam ao todo, uma média de dois salários mínimos. 
Consumo alimentar e cultura material: um estudo sobre distinções e escolhas alimentares entre moradores de um conjunto habitacional popular.

Revista Ensaios, vol. 13, jul-dez de 2018. ISSN 2175-0564.

$\mathrm{Na}$ ocasião da visita, a moradora fez questão de abrir sua geladeira e dispensa e mostrar tudo o que havia dentro. Estavam cheias de mantimentos. Em relação às despesas de condomínio, tarifas de conta de luz e gás, mostram-se a todo o momento de acordo em pagálas.

Ter as coisas contadas dentro de casa, principalmente na geladeira e no armário da cozinha, é realmente uma coisa que não tem a ver comigo. Pode faltar o que for na minha casa, mas comida eu faço questão de comprar mais do que eu vou precisar para o dia seguinte. Eu posso abrir a minha geladeira na frente de qualquer um que não vai me fazer vergonha. Eu já separei o valor que eu recebo do Bolsa Família delas [das netas] pra comprar só coisas que elas gostam e precisam comer: iogurte, carne, leite, biscoito, frutas e saladas. Quando era a mãe delas que recebia, ela pegava o dinheiro pra ela e só gastava com besteira. Comigo não. Faço questão que elas tenham uma alimentação saudável (Dona Gisela).

Miller (2002; p.162) analisa que as compras no supermercado são sempre marcadas pelo signo da alteridade, já que dirigidas aos outros: filhos, companheiros ou à própria casa. $\mathrm{O}$ autor entende o mote dos atos de compra cotidianos como sendo o amor devocional.: "o ato de comprar é a interpretação do outro como sujeito que deseja".

O campo empírico reafirmou um senso comum na sociedade brasileira, sobretudo no que se refere a um valor de classe: ter uma dispensa e geladeiras cheias indica distinção social, orgulho, sensação de dever cumprido ao poder comprar além do considerado necessário, como o arroz e o feijão. Alimentar os filhos e "dar o melhor" à eles é um imperativo categórico. O contrário é sinônimo de desespero, irresponsabilidade e fracasso.

\section{Considerações finais}

A comida possui uma enorme centralidade objetiva e simbólica, pois trata-se de uma dimensão importante da identidade nacional, especialmente nas camadas populares, não exatamente pela função da sobrevivência, mas, sobretudo, pelo aspecto mais intangível da comida, que são as diferentes formas de sociabilidades e prazeres a ela relacionados e no comer juntos - a comensalidade. A comida e o comer tornaram-se, no mundo contemporâneo, fontes legítimas de reflexividade e adquiram maior centralidade para a compreensão das múltiplas e complexas possibilidades de classificação do mundo social. Muito além de uma 
Consumo alimentar e cultura material: um estudo sobre distinções e escolhas alimentares entre moradores de um conjunto habitacional popular.

Revista Ensaios, vol. 13, jul-dez de 2018. ISSN 2175-0564.

necessidade biológica, a alimentação forma um sistema de hábitos, ritos, costumes, crenças e estilos de vida. A escolha do alimento, que se transformará em comida através de diferentes processos culturais, não se dá de forma aleatória, o que nos faz retomar e atualizar a clássica dualidade "comida versus alimento", muito bem problematizada por Roberto Da Matta, o que significa que o alimento é o estado bruto daquilo que será transformado em comida, através do preparo e do gosto, que é construído socialmente.

A pesquisa de cunho etnográfico realizada no conjunto habitacional PAC do Morro do Preventório sobre consumo doméstico identificou que a mudança no padrão através dos relatos dos moradores, que a hierarquia de prioridades das despesas a serem pagas obedecia à seguinte ordem: gastos com alimentação, pagamento da conta de gás, pagamento da conta de luz, gastos de ordem pessoal e taxa de condomínio. Durante as conversas e entrevistas em profundidade que foram realizadas com os sessenta e cinco moradores, a temática da alimentação inevitavelmente perpassou diferentes assuntos: desde as novas contas a serem pagas até a compra de mobílias e eletrodomésticos para a cozinha. Para o inconsciente coletivo local, morar em um apartamento significava adquirir novos bens e assumir despesas até então inexistentes. A reconfiguração espacial dos apartamentos em relação à moradia na favela alterou não apenas o ideário de conforto e status quo dos moradores. Alterou a forma de aquisição, circulação e consumo dos alimentos.

A comida possui uma enorme centralidade objetiva e simbólica na vida desses moradores, como de resto em toda a sociedade brasileira, pois trata-se de uma dimensão importante da identidade nacional, especialmente nas camadas populares, não exatamente pela função da sobrevivência, mas, sobretudo, pelo aspecto mais intangível da comida, que são as diferentes formas de sociabilidades e prazeres a ela relacionados e no comer juntos - a comensalidade.

Para lidar com os aspectos socioculturais da alimentação contemporâneas, é necessário sublinhar de que maneira a dimensão simbólica e a material se cruzam e se conformam. Essa linha de análise nos ajuda a compreender que não é possível lidar com o cenário atual a partir de uma única narrativa, seja ela a da "homogeneização" ou "pluralidade" dos costumes e práticas alimentares. Ambas as dimensões convivem lado a lado e em conflito. 
Consumo alimentar e cultura material: um estudo sobre distinções e escolhas alimentares entre moradores de um conjunto habitacional popular.

Revista Ensaios, vol. 13, jul-dez de 2018. ISSN 2175-0564.

\section{REFERÊNCIAS BIBLIOGRÁFICAS}

BARBOSA, Lívia. Feijão com arroz e arroz com feijão: o Brasil no prato dos brasileiros. Horizontes antropológicos, 2007, vol.13, n.28, pp.87-116.

BARBOSA, Lívia. Sociedade de Consumo. Rio de Janeiro: Jorge Zahar, 2004.

BRUSCHINI, Maria Cristina A. Articulação trabalho e família: famílias urbanas de baixa renda e políticas de apoio às trabalhadoras. São Paulo: FCC/ DPE, 2008.

BOURDIEU, Pierre. A Distinção: crítica social do julgamento. São Paulo: Zouk, 2007. Vozes, 2009.

A casa ou o mundo invertido. In: BOURDIEU, P. O senso prático. Petrópolis:

CANESQUI, Ana Maria. Mudanças e permanências da prática alimentar cotidiana de famílias de trabalhadores. In: Canesqui, A. M. e Garcia, R. W. D. (orgs.) Antropologia e Nutrição: um diálogo possível. Rio de Janeiro, Edi- tora FIOCRUZ, 2005, pp.167-210.

CRONIN, James M.; MCCARTHY, Mary B.; COLLINS, Alan M. Covert distinction: how hipsters practice food-based resistance strategies in the production of identity Consumption Markets \& Culture, vol. 17, n. 1, 2014, p.2-28.

DAMATTA, Roberto. O que faz o brasil, Brasil? Rio de Janeiro: Rocco: 1986.

DOUGLAS, Mary. Pureza e perigo. Lisboa, Edições 70, 1991.

DOUGLAS, Mary; NICOD, Michael.Taking the biscuit: The structure of British meals New Society 19, 1974, p. 744-747.

ELIAS, Norbert, O Processo Civilizador: uma história dos costumes. Rio de Janeiro: Jorge Zahar Editor, vol. 1, 1990.

FISCHLER, Claude. L’Homnivore. Paris: Odile Jacob, 1990.

GARSON, Marcelo.; TORQUATO, Shirley. Alimentação e Ciências Sociais: Perspectivas contemporâneas. Rio de Janeiro, Autografia, 2018.

GOODY, Jack. Cozinha, culinária e classes: um estudo de sociologia comparativa. Lisboa, Celta: 1998.

LEVI-STRAUSS, Claude. Antropologia Estrutural. Rio de Janeiro: Tempo Brasileiro, 1975.

LÉVI-STRAUSS, Claude. O triângulo culinário. In: SIMONIS, Ivan. Introdução ao estruturalismo: Claude Lévi-Strauss ou a paixão do incesto. Lisboa: Moraes, 1979. 
Consumo alimentar e cultura material: um estudo sobre distinções e escolhas alimentares entre moradores de um conjunto habitacional popular.

Revista Ensaios, vol. 13, jul-dez de 2018. ISSN 2175-0564.

MACIEL, Maria Eunice. Churrasco à gaúcha. Horizontes Antropológicos, vol.2. 2, $\mathrm{n}^{\text {o }} 4$, Porto Alegre-RS, UFRGS, 1996, pp.34-48.

MAUSS, Marcel. As técnicas do corpo. In: Sociologia e antropologia. São Paulo: Cosac \& Naify, 2003.

MENNELL Stephen. All Manners of Food: Eating and Taste in England and France from the Middle Ages to the Present. Oxford: Blackwell, 1985.

MILLER, Daniel. A teoria das compras. O que orienta a escolha dos consumidores. São Paulo, Nobel, 2002.

MILLER, Daniel. Trecos, troços e coisas. Estudos antropológicos sobre a cultura material. Rio de Janeiro: Zahar, 2013.

MOTA, Fabio. O Estado contra o Estado: Direito, Poder e Conflitos no Processo de Produção da Identidade 'Quilombola' da Marambaia. In: KANT DE LIMA, Roberto (Org.). Antropologia e Direitos Humanos \&. Niterói: EdUFF, 2005.

MINTZ, Sidney. Comida e Antropologia: uma breve revisão. Revista Brasileira de Ciências Sociais, vol. $16, n^{\circ} 47$, p. $31-41$

MOHRING, Maren. Transnational Food Migration and the Internationalization of Food Consumption: Ethnic Cuisine in West Germany“. In: NÜTZENADEL, Alexander; TRENTMANN, Frank (eds.): Food and Globalization: Consumption, Markets and Politics in the Modern World, Oxford/New York: Berg, 2008, p. 129-150.

RIAL, Carmen. Fast-food: a nostalgia da estrutura perdida. Horizontes Antropológicos, número 4, 1996, p.94-103.

SANTOS, Wanderley Guilherme dos. Cidadania e Justiça: a política social na ordem brasileira. Rio de Janeiro: Ed. Campus, 1979.

SIMMEL, Georg. The sociology of meal. In: Simmel on culture: selected writings. Londres: Sage, 1997.

TORQUATO, Shirley Alves. Casa nova, vida nova: Consumo, despesas e orçamento doméstico entre moradores do PAC do Morro do Preventório. Tese de Doutorado Niterói, Programa de Pós Graduação em Antropologia, Universidade Federal Fluminense, 2013.

ZUBAIDE, Sami; TAPPER, Richard. Culinary Cultures of Middle East.Oxford: I. B. Tauris \& Company, 1996.

WOORTMAnN, K. Casa e família operária. Anuário Antropológico 80. Fortaleza e Rio de Janeiro: Tempo Brasileiro, UFCE, 1982. 